\title{
Representação do Mito do Ataíde nas Vozes de Crianças na Comunidade Ribeirinha do Castelo em Bragança - PA
}

\author{
Kátia CRegina Morais de Eliveira* \\ Maiara da filva CReis** \\ Raquel Atmorim dos $\delta_{\text {antos }}^{* * *}$
}

\section{RESUMO}

Este trabalho objetiva investigar a representação do mito do Ataíde nas vozes das crianças por meio da produção de narrativas e histórias em quadrinhos com a turma de $6^{\circ}$ ano/9, na Escola Municipal de Ensino Fundamental Maria Augusta Corrêa da Silva, localizada na comunidade pesqueira do Castelo em Bragança-PA. O referencial teórico-metodológico fundamentou-se em Chartier (1988), Socorro (2010), Eliade (1972) e Santos (1994). A pesquisa é de cunho qualitativo, foi utilizado como instrumento de coleta de dados o questionário com perguntas abertas, assim como produção textual de narrativas e produção de histórias em quadrinhos sobre o mito do Ataíde. Os sujeitos foram cinco alunos com idade entre onze e doze anos. Concluímos que o mito do Ataíde é

*Graduanda em Pedagogia; Bolsista do Núcleo de Estudos e Pesquisas sobre Educação, Currículo, Formação de Professores e Relações Étnico-Raciais, e-mail: katia_rmoliveira@hotmail.com.

** Graduanda em Pedagogia; Bolsista do Núcleo de Estudos e Pesquisas sobre Educação, Currículo, Formação de Professores e Relações Étnico-Raciais, e-mail: maiara.silva75@yahoo.com.br.

*** Professora Adjunta da Universidade Federal do Pará, Campus Bragança, Faculdade de Educação (FECED/UFPA). Coordenadora do Projeto de Monitoria sobre Currículo, Didática e Formação Docente e suas interfaces com as Relações Étnico-Raciais: construção colaborativas de práticas pedagógicas. Coordenadora do Núcleo de Estudos e Pesquisas sobre Educação, Currículo, Formação de Professores e Relações ÉtnicoRaciais, e-mail: rakelamorim@yahoo.com.br

@rquivo Brasileiro de Educação, Belo Horizonte, v. 6, n. 14, mai-ago, 2018. 
representado nas vozes das crianças com características de monstro que apresenta atitudes humanas, assim como este ser sobrenatural tem 0 poder de regular as ações e comportamento do homem para manter seu habitat protegido. Para tanto, as gerações mais novas garantem a permanência dessa cultura local, as quais ao ouvir, contar e recontar a história do meio homem-meio animal conseguem dar significado e sentido a identidade desse povoado ribeirinho.

Palavras-chave: Representação. Mito do Ataíde. Crianças.

\section{ABSTRACT}

The purpose of this service was to investigate the representation of the public in children's classes for the production of narratives and comics with the group of 6th grade year, at the Maria Augusta Corrêa da Silva Municipal School of Education, located in the fishing community of the Castle in Bragança -PAN. The theoretical-methodological framework was based on Chartier (1988), Socorro (2010), Eliade (1972) and Santos (1994). The research is qualitative, it was used as a data collection tool and the opening questionnaire, just as it was produced text of narratives and production of comics about the Ataide myth. The students were five students aged between eleven and twelve. What is best to represent children with the characteristics of monster that presents human attitudes, just as this supernatural has the power to regulate man's actions and behavior to keep his habitat protected. To this end, as the younger ones guarantee the permanence of this local culture, as in listening, telling and recounting the story of the half man-half animal, they can give meaning and meaning to the word of the riparian village.

Keywords: Representation. Myth of Ataide. Children

\section{INTRODUÇÃO}

Esse estudo analisa a Representação do Mito do Ataíde nas vozes das Crianças na Escola Maria Augusta Corrêa da Silva na Comunidade Ribeirinha

@rquivo Brasileiro de Educação, Belo Horizonte, v. 6, n. 14, mai-ago, 2018. 
do Castelo em Bragança-PA. Originou-seda participação no Projeto de Monitoria em Teorias do Currículo, Didática e Formação Docente e suas Interfaces com as Relações Étnico-Raciais: Construção Colaborativa de Práticas Pedagógicas, articulado ao Núcleo de Estudos e Pesquisa em Educação, Currículo, Formação de Professores e Relações Étnico-Raciais (NEAFRO), financiado pela Pró-Reitoria de Ensino de Graduação (PROEG)da Universidade Federal do Pará, Campus Bragança.

O estudo objetivou investigar a representação do mito do Ataíde nas vozes das crianças por meio da produção de narrativas e histórias em quadrinhos com a turma de $6^{\circ}$ ano/9, na Escola M.E.I.F Maria Augusta Corrêa da Silva, localizada na Comunidade Pesqueira do Castelo, bem como perceber de que forma se configura o mito do Ataíde segundo a concepção das crianças, identificar de que forma as crianças expressam o mito do Ataíde por meio das narrativas produzidas e, por fim interpretar a representação do mito do Ataíde pelas crianças retratadas nas histórias em quadrinhos.

O Projeto de Monitoria permitiu a participação direta no ambiente escolar e assim investigar diferentes propostas que pudessem contribuir com a formação acadêmica docente. No decorrer da participação na escola de Educação Básica percebemos a valorização do imaginário amazônico nas vozes das crianças bragantinas, a partir das memórias de velhos [re]contadas as crianças da comunidade ribeirinha do Castelo em Bragança-PA.

Nessas memórias observamos que o Mito do Ataíde se configurou como uma narrativa fortemente presente entre as pessoas mais velhas das comunidades ribeirinhas na região bragantina. Segundo A LENDA..., (2012), o Ataíde é um ser negro monstruoso, com jeito de homem, mas imenso (maior que um homem médio com os braços estendidos), possui ventas de porco, corpo feito de lama e órgão genital bastante avantajado, chegando a

@rquivo Brasileiro de Educação, Belo Horizonte, v. 6, n. 14, mai-ago, 2018. 
encostar no chão. Segundo a população, esse ser habita nas várzeas, alagados e os manguezais por todo o litoral do estado do Pará.

O Ataíde é um ser que não reage de forma animal com aqueles que vivem dos manguezais ou utilizam os recursos naturais de forma sustentável, entretanto já aqueles que não preservam o ambiente e não respeitam o período de extração dos recursos naturais característicos desse ambiente, sua vingança é terrível e violenta. Seus desafetos são estuprados sem piedade, suas vítimas são levadas a morte e seus corpos são abandonados no mangue. Vale ressaltar que não existe uma imagem muito boa sobre sua fisionomia, alguns dizem que seu corpo é coberto de pelos, outros dizem que ele é um ser que tem a fisionomia de um homem e que seu órgão genital é desproporcional ao seu corpo levando enrolado ao pescoço(A LENDA..., 2012).

Dessa forma, fica subtendido que muitos pais ao recontarem o mito para seus filhos omitem detalhes de suas características pelo fato de envolver situações que trazem o sexo implícito, assim como teria que relatar o estupro como uma vingança executada pelo dono dos manguezais. Ainda que a lenda do Ataíde para maioria dos pais seja imprópria para a idade das crianças, elas conseguem absorver suas características e suas práticas dentro da própria comunidade, uma vez que este elemento é muito citado nas rodas de conversa, principalmente das famílias ribeirinhas, pois geralmente os diálogos estão interligados ao equilíbrio da retirada das atividades de pesca e extração de caranguejo, a qual deixam claro que se agirem de forma exacerbada terão consequências. Sendo assim, o mito do Ataíde emerge também para regular as ações do homem em relação as práticas exploradoras no seu ambiente de moradia, pois este é um defensor do mangue e que sua manifestação é para proteger e preservar o ambiente natural.

Nesse obstante, as narrativas sobre o mito do Ataíde e seu

@rquivo Brasileiro de Educação, Belo Horizonte, v. 6, n. 14, mai-ago, 2018. 
reconhecimento e valorização enquanto memória surgiu a curiosidade de investigar de que forma o Mito do Ataíde é representado nas vozes das crianças. Uma vez que o mito é a "[...] linguagem fundadora, a fantasia matriz, a estrutura primordial, uma analogia que se faz entre a leitura de mundo e a vida" (SOCORRO, 2010, p.6). Essa linguagem mitológica navega entre as águas e mangues das comunidades ribeirinhas na região bragantina no estado do Pará como uma história que atravessa gerações por meio da oralidade.

Diante dessa narrativa repassada por membros da família e por pessoas mais velhas dentro da própria comunidade e em especial por aqueles que sobrevivem da pescaria, as crianças encontram-se enquanto sujeitos ouvintes que garantem essa memória. Nessa perspectiva, o mito:

[...] conta uma história sagrada, ele relata um acontecimento ocorrido, [...]um fato que passou a existir; seja uma realidade absoluta, ou apenas um fragmento. É sempre, portanto o conto de uma criação: ele narra de que modo algo foi produzido e começou a ser (ELIADE, 1972, p.9).

A representação possibilita que o mito se torne um elemento vivo na memória das diferentes gerações, uma vez que o uso dos símbolos e signos são essenciais para justificar a existência dessa narrativa. Assim

Os signos possibilitam a troca do elemento ausente, substituída pela imagem, que reconstrói a figura tal como ela é. Essa possibilidade do uso da representação simbólica, contribui para valorização de crenças, ritos que podem ser vistos a partir interpretação da subjetividade (CHARTIER, 1988, p.20).

O mito se conduz como uma crença, que é normalmente narrada no cotidiano dos ribeirinhos como algo verdadeiro, como um fato existente, que se espalha entre adultos e crianças. A figura da criança apresenta uma relação de aproximação com essas narrativas, pois suas vivências e contato com a natureza permitem que essa crendice mitológica tenha garantia

@rquivo Brasileiro de Educação, Belo Horizonte, v. 6, n. 14, mai-ago, 2018. 
entre as gerações mais nova. Baseado nesse argumento, a pesquisa metodologicamente ocorreu de diferentes formas.

\section{PERCURSO METODOLÓGICO}

Essa pesquisa se caracteriza enquanto pesquisa qualitativa, uma vez que esta possibilita a interpretação, a compreensão e a aproximação entre pesquisador e pesquisado. Na concepção Minayo(2011) a pesquisa qualitativa empenha-se como universo de significados, motivos, aspirações, crenças, valores e atitudes, o que possibilita um espaço mais intenso de relações, de processos e de acontecimentos que não podem ser reduzidos à operacionalização de variáveis.

Utilizamos como instrumento de coleta de dados o questionário aberto, produção textual de narrativa e construção de histórias em quadrinhos. Olócus da pesquisa se deu na Escola Municipal de Ensino Fundamental Maria Augusta Corrêa da Silva, localizada na comunidade ribeirinha do Castelo a margem do rio Taperaçu-Porto, no município de Bragança-PA. Para esse processo, de construção foram selecionados cinco alunos do $6^{\circ}$ ano/9 com idade entre onze e doze anos, porém a seleção dos alunos se deu pelos critérios de idade, por série, domínio da leitura e escrita e também por indicação da gestão escolar por já conhecerem as turmas que mais se adequariam participar da pesquisa.

A pesquisa ocorreu em diferentes etapas: na primeira foi realizada uma visita na Escola Municipal de Ensino Infantil e Fundamental Maria Augusta Corrêa da Silva para a autorização da pesquisa junto a Gestão da escola e Coordenação Pedagógica e a apresentação da proposta de trabalho. Concomitantemente, nesse momento foi ressaltado acerca da importância dessa pesquisa para a comunidade, para o campo científico e de sua contribuição para a valorização cultural dessas narrativas nesse espaço de

@rquivo Brasileiro de Educação, Belo Horizonte, v. 6, n. 14, mai-ago, 2018. 
convivência com o mangue.

O estudo trouxe como ponto de partida a importância em considerar o contexto particular em que se desenvolvem as práticas educacionais e socioculturais contemplando os diferentes pontos de vista dos grupos que se relacionam a situação estudada. Toda pesquisa não é "[...] nada de absolutamente original, portanto, mas um modo diferente de olhar e pensar determinada realidade a partir de uma experiência e de uma apropriação do conhecimento[...]"(DUARTE, 2002, p.1).

Os conhecimentos científicos são produzidos em uma sociedade e esta produção e sua veiculação/socialização está interligada às formas como certas relações sociais e de poder se estruturam, tanto em nível mais geral, como nos pequenos grupos ou em nichos institucionais (GATTI, 2001). Dessa forma, a pesquisa qualitativa é comunicativamente trabalhada e retrabalhada, para que duas condições sejam satisfeitas: a confiança que o entrevistado deve ter em relação do que falou e o ponto de vista do entrevistado.

No segundo momento conhecemos a turma, explicamos o objetivo do projeto e iniciamos as atividades propostas, porém os pais ou responsáveis assinaram uma documentação autorizando a participação dos seus filhos na pesquisa. Em detrimento a essa assertiva, iniciamos o trabalho de pesquisa com os alunos.Explicamos para as crianças como seria o processo de desenvolvimento da pesquisa e em seguida iniciaram com a produção da narrativa do mito do Ataíde,após a produção de histórias em quadrinhos e por fim responderam um questionário com perguntas abertas. No decorrer das atividades percebemos o envolvimento dos alunos em participar das atividades referentes a narrativa, assim como os cuidados na elaboração dos desenhos em quadrinhos, para que pudessem representar o Ataíde tal como imaginavam.

@rquivo Brasileiro de Educação, Belo Horizonte, v. 6, n. 14, mai-ago, 2018. 


\section{MEMÓRIAS E GERAÇÕES: UMA CONSTRUÇÃO SOCIAL DO MITO}

O mito do Ataíde permeia entre as vozes das comunidades ribeirinhas, atravessando as gerações menores. Estas gerações resguardam um valor cultural fruto da crença em seres fantásticos sem nunca ter visto, mas por ter ouvido suas histórias. Entretanto, são capazes de caracterizar esse representante mitológico que vive nas áreas de manguezais, the apresentando significados e sentidos. Para Chartier (1991) a representação é uma relação decifrável é, portanto, postulada entre o signo visível e o referente significado. Nesse cenário se visibiliza a existência dos fenômenos, os quais podem ser decodificados e interpretados por diferentes gerações ribeirinhas. Nessa perspectiva, as falas seguintes serão analisadas a partir dos questionários respondidos pelos entrevistados.

Dessa forma, aluna Leandra'de 12 anos descreve o Ataíde "como um homem revestido de bicho, moreno alto e traz medo para todo mundo". Ainda acrescenta que ele "mata as pessoas"e que essa história aprendeu com o avô. Mediante essa narrativa, O Ataíde é apresentado com características humanas e animalescas que causam lesões físicas aos sujeitos, por conta disso proporcionam grande medo àqueles que vivem em redor do manguezal. Assim, é perceptível a presença da narrativa sendo repassada no ambiente familiar.

O imaginário alimentado entre as gerações se concebe com palavras relatadas, construindo sentidos e representações que possibilitem a interpretação do mundo e a existência do ser fantástico que explica a existência da história de uma determinada comunidade. Para Socorro (2010) o mito é considerado como fábula central, leitura analógica do mundo e da vida. Essa analogia entre o cosmo e a vida se explica na capacidade do homem reescrever o fabuloso, o não visível, por meio do que foi dito.

${ }^{1}$ No decorrer da pesquisa serão utilizados pseudônimos, para que a identidade dos sujeitos seja resguardada.

@rquivo Brasileiro de Educação, Belo Horizonte, v. 6, n. 14, mai-ago, 2018. 
Com essa transmissão dita de forma oralizada à entrevistada Leandra descreve que "o Ataíde é um monstro que vive no manguezal, que "encanta" as pessoas". Diante da concepção da aluna, o Ataíde é puramente animal, que tem seu espaço de moradia em ambiente natural, e que seduz sua vítima por meio de encantos. Para tanto, essa narrativa mitológica nem sempre é transmitida no ambiente familiar.

Essa recriação do impalpável revela a capacidade de reproduzir as formas físicas do memorável e manter viva a crença entre essas crianças, uma vez que nem sempre essa transmissão histórica se aprende com a família. Socorro (2010) ainda afirma que o mito é entendido como explicação para a vida, a natureza, a história e as relações sociais do homem em seu espaço de origem.

Na percepção da entrevista da Almir ao Ataíde "é um homem, é um bicho da mata, que encanta as pessoas, que ele faz muita coisa e até pesca". Ainda acrescenta "as pessoas contaram para mim". Nesse dialogo a criança acredita que o Ataíde apresenta natureza masculina, que vive na floresta e utiliza de formas sobrenaturais para se aproximar das pessoas que encontra no espaço de sua convivência. Além disso, acorda que o mesmo envolve-se em várias atividades, assim como realizada a prática da pesca como de costume do homem ribeirinho.

Nesse discurso a memória do mito do Ataíde entre as gerações mais novas é garantida pela oralidade e permanência dessa cultura. Santos (1994), expressa que a cultura é fruto de um processo social, que exige respeito, uma vez que é produto coletivo da humanidade.

O conhecimento tradicional dessas comunidades pode ser definido como "[...] o conjunto de saberes e saber-fazer a respeito do mundo natural, sobrenatural, transmitido oralmente de geração em geração" (DIEGUES et al., 2000, p.30). A relação com a natureza, a forma com que praticam suas atividades produtivas, o conhecimento sobre os espaços apropriados -

@rquivo Brasileiro de Educação, Belo Horizonte, v. 6, n. 14, mai-ago, 2018. 
território -, a liberdade, a propriedade dos meios de produção, dentre outras características, asseguram o modo de vida tradicional dessas comunidades, a exemplo das comunidades tradicionais pesqueiras.

Dessa maneira, desde cedo as crianças criam um vínculo de pertencimento e respeito com ambiente onde mora, por meio das histórias que são contadas a construção de sua personalidade é formada. É no desenvolvimento dessas relações, com características específicas, que observamos as comunidades tradicionais pesqueiras construindo suas territorialidades, marcadas por valores simbólicos e materiais que direcionam seu uso, controle e proteção.

Despertar o imaginário significa navegar na lembrança, na memória, no passado, em gerações e embarcar entre rios e mangues, onde se constrói as histórias transmitidas pela fala. Nesse embarque o mito é uma narrativa viva em meio às populações que garantem sua existência e são responsáveis por sua continuidade. As narrativas consideráveis inimagináveis, sem veracidade, apresentam sentido próprio, de representatividade da linguagem de um povo, onde seus significados compartilham e proporcionam sentidos que estão para além da busca de uma verdade. As narrativas mitológicas vão garantindo seu espaço nas vozes das crianças, as quais culminam com o valor cultural presente entre mangues e rios.

Em complemento a analise dos questionários, as produções textuais fizeram parte dessa construção de narrativa, a qual os discentes puderam expressar por meio das produções textuais as histórias do mito do Ataíde aprendidas no decorrer da convivência com pessoas que cotidianamente relatam fatos vivenciados ou repassados por outras gerações.

A produção escrita possibilitou a criança mergulhar nessa crença mitológica mundo fantástico, a qual deixou emergir o aprendido e apreendido na oralidade e convivência com os mais idosos dentro de uma mesma comunidade. Logo:

@rquivo Brasileiro de Educação, Belo Horizonte, v. 6, n. 14, mai-ago, 2018. 
Os Conhecimentos locais são fundamentais para garantir a continuidade destas populações. [...] utilizam-se dos saberes da tradição acumulados pela experiência, observação da natureza e transmissão oral. Sistema mutável de informações que são adquiridas ao longo do tempo em função de conhecimentos, de práticas, de valores e de experiências individuais e coletivas do grupo social, da comunidade (VIEIRA et al., 2015).

Diante disso, a transmissão dessa cultura oralmente concebida entre adultos e crianças se fortalece quando reproduzidas. Nessa perspectiva, a entrevistada relata um acontecimento ocorrido na pancada de uma praia conhecida como Maceió, no qual expressa: "o Ataíde estuprou um homem e quando o Ataíde estupra as pessoas ele joga seu encanto" (ALUNA ALMIRA). Nessas considerações se enfatizam o poder que a oralidade apresenta em comunidades as margens de manguezais

Nessa perspectiva, a entrevistada traz informações acerca de um ser mitológico que se comporta de forma violenta com suas vítimas, o qual se apropria de seus encantos para aproximar-se e violentá-las sexualmente. Assim, se evidencia que essas narrativas muitas vezes são repassadas por uma pessoa mais velha que faz parte da família. Desse modo, as crianças conseguem reproduzir a narrativa do mito do Ataíde por meio da produção textual escrita, recriando essa história cultural em quadrinhos também é uma das formas em que os personagens infantis conseguem transmitir a relevância das interpretações do mundo do mito.

\section{MITO DO ATAÍDE EM QUADRINHOS: UMA RECRIAÇÃO CULTURAL}

Os fatos, as histórias, as estórias, os acontecimentos sendo eles do mundo fantástico, mitológico, verídico ou não, são elementos que podem ser retratados por meio de diferentes gêneros discursivos. Logo, as histórias em quadrinhos são gênero por apresentarem uma linguagem verbal e imagética com capacidade de retratar personagens, acontecimentos,

@rquivo Brasileiro de Educação, Belo Horizonte, v. 6, n. 14, mai-ago, 2018. 
tempo e espaço que podem ser interpretadas a partir da leitura(MOYA, 1994).

De acordo com Moya (1994) o quadrinho apresenta caráter imagístico ou relato, que se integra a conotações dos textos escritos, numa perfeita identificação e entrosamento das duas formas de linguagem: a palavra e o desenho. Partindo desse pressuposto, as histórias em quadrinhos possibilitam a integração das crianças ao mundo mitológico, no qual representam por meio das imagens e falas o sujeito que vive no mangue, assim como suas práticas contra aqueles que comungam do mesmo espaço para sobreviver. Assim como expressam as imagens em quadrinhos.

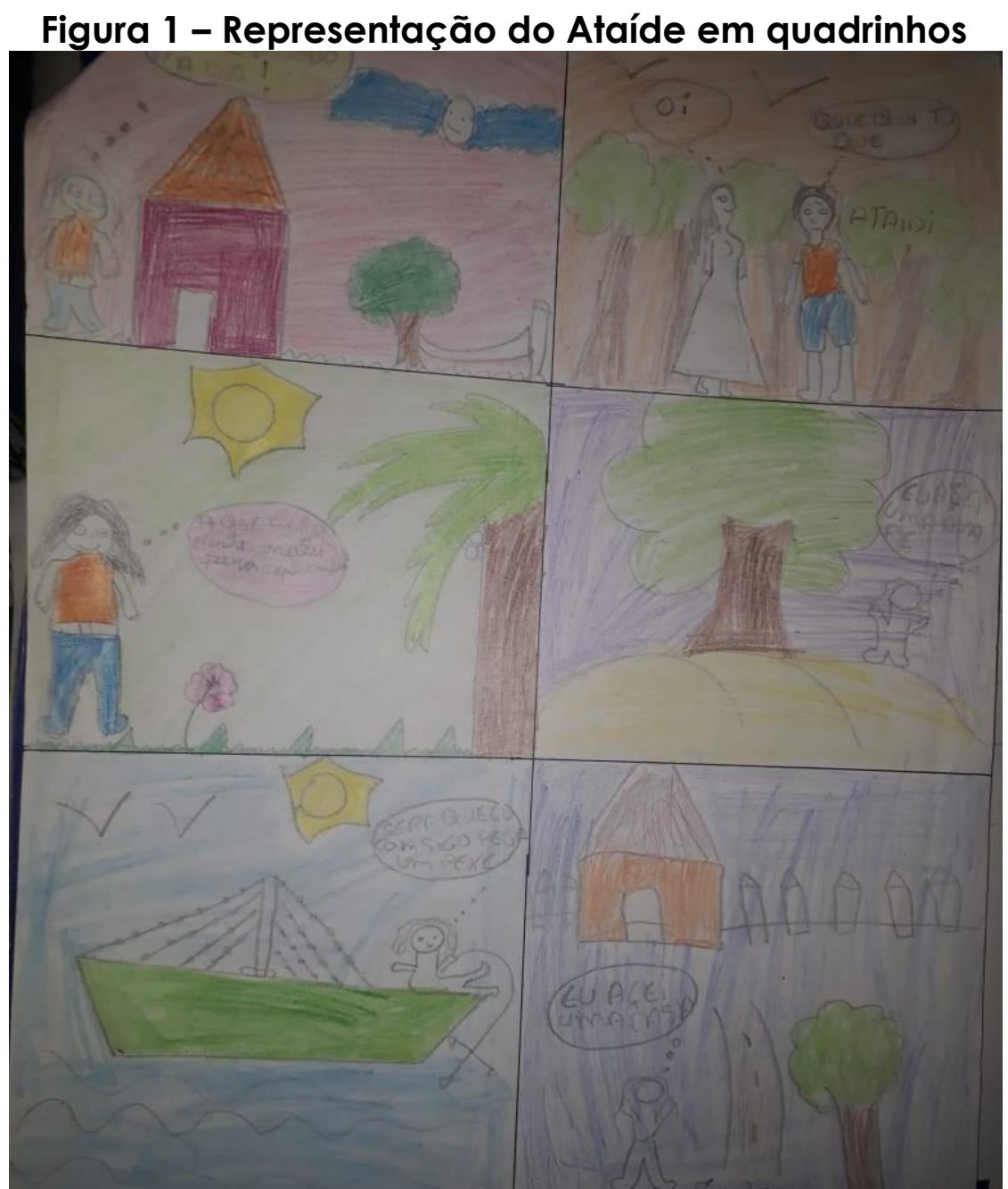

Fonte: Produção de crianças sobre o mito do Ataíde (2018)

@rquivo Brasileiro de Educação, Belo Horizonte, v. 6, n. 14, mai-ago, 2018. 
De acordo com a figura 1 a criança traz na história em quadrinho o Ataíde no meio da mata e em contato com os seres humanos, inclusive com mulheres; assim como demonstra que o mesmo protege o ambiente que vive, exercendo atividade de pescador, assim como representa o ser mitológico também em contato com a comunidade local. Para tanto, percebe-se que o Ataíde é apresentado com características humanas e realiza as mesmas práticas que são realizadas por pescadores, assim como se identifica a existência da comunicação entre homem e o ser sobrenatural. Diante dessas considerações, o "Ataíde é uma figura sobrehumana, protetora do manguezal, de genitália gigantesca, a qual castiga transgressores ambientais" (VIEIRA, 2015, p.10).

Figura 2 - Representação do Ataíde em quadrinhos

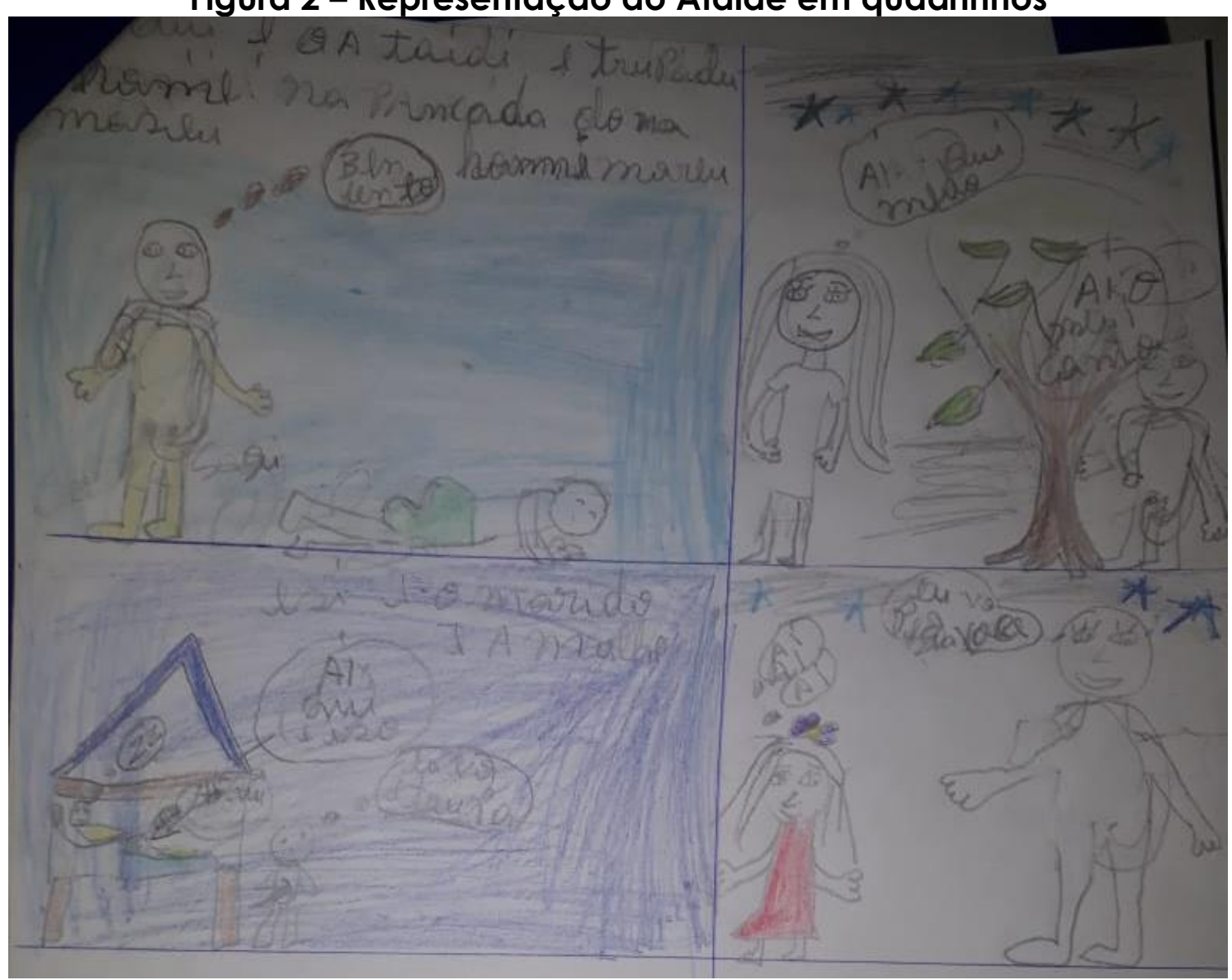

Fonte: Produção de crianças sobre o mito do Ataíde (2018)

@rquivo Brasileiro de Educação, Belo Horizonte, v. 6, n. 14, mai-ago, 2018. 
Na figura 2 o Ataíde é retratado como um ser fantástico violento, sua parte intima de tamanho exagerado enrolado ao pescoço, o qual causa muito medo tanto para mulheres quanto para os homens. Nesse sentido, a imagem apresenta um casal descansando em um rancho e que o Ataíde não se intimida em retrucar que vai estuprá-los. Percebe-se que o Ataíde apresenta uma relação de proteção com o ambiente dos manguezais e que não tem afinidade harmoniosa com aqueles que exploram o seu habitat natural. Ainda de acordo com o exposto, a relação sexual praticada é desumana e leva a morte.

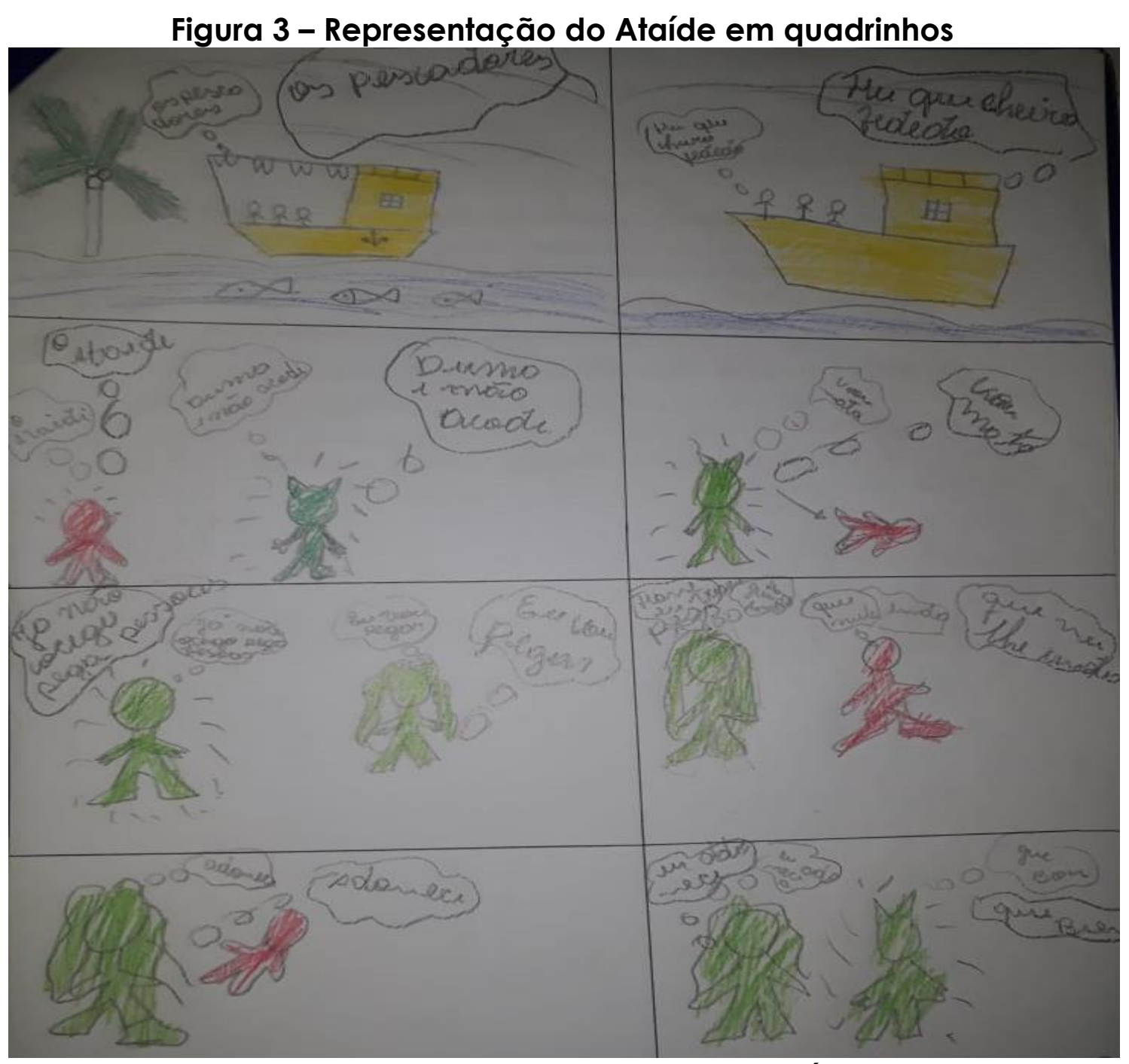

Fonte: Produção de crianças sobre o mito do Ataíde (2018)

@rquivo Brasileiro de Educação, Belo Horizonte, v. 6, n. 14, mai-ago, 2018. 
A figura 3, expressa que durante as atividades pesqueiras realizadas nas proximidades dos manguezais, os pescadores sentem o odor fétido do Ataíde, os quais sentem bastante medo, pois quando se aproxima dos pescadores informa que vai adormecê-los e matá-los. Nessa apresentação histórica por meio de desenho foi enfatizado que o Ataíde é percebido pelos pescadores pelo cheiro forte que apresenta, e que ainda encanta sua vítima.

Figura 4 - Representação do Ataíde em quadrinhos

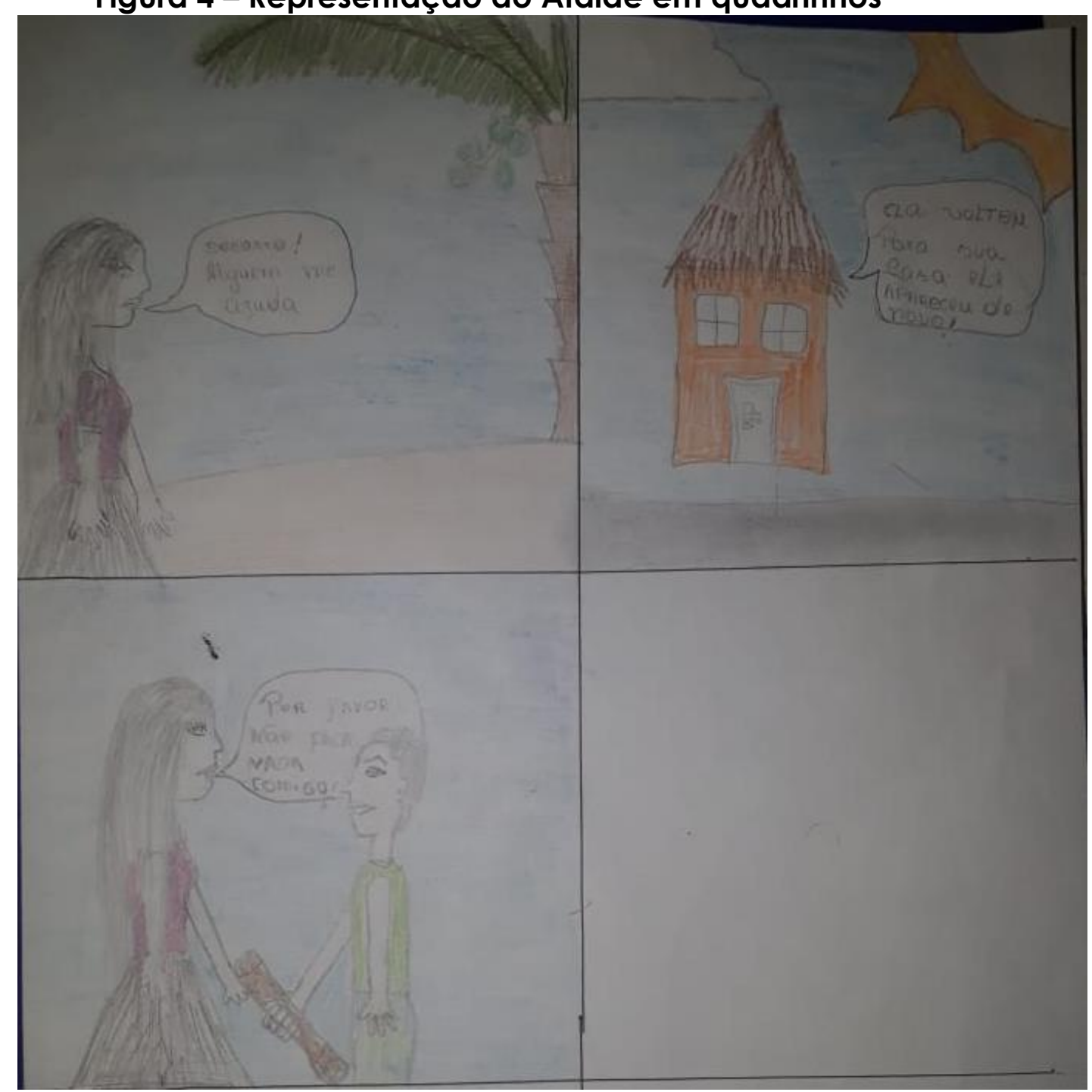

Fonte: Produção de crianças sobre o mito do Ataíde (2018)

@rquivo Brasileiro de Educação, Belo Horizonte, v. 6, n. 14, mai-ago, 2018. 
De acordo com a Figura4 a aluno retrata o ser simbólico como um ser que assusta as mulheres que residem às proximidades do mangue e que pode realizar o ataque várias vezes com a mesma vítima. Segundo a imagem, a vítima ao encontrar-se de frente com ○ Ataíde sente-se amedrontada, por saber o tipo de pratica que ele realiza.Com isso, Rocha (1996, p.3) assevera que "[...] o que marca o ser humano é justamente sua particularidade de possuir e organizar símbolos que se tornam linguagens articuladas, aptas a produzir qualquer tipo de narrativa".

Rocha (1996, p.4)ainda considera que o "mito faz parte daquele conjunto de fenômenos cujo sentido é difuso, pouco nítido múltiplo. Serve para significar muitas coisas, representar várias ideias, ser usado em diversos contextos." Nessa vertente, subtende-se que o mito é visto de forma particular pelos interpretadores.

@rquivo Brasileiro de Educação, Belo Horizonte, v. 6, n. 14, mai-ago, 2018. 
Figura 5 - Representação do Ataíde em quadrinhos

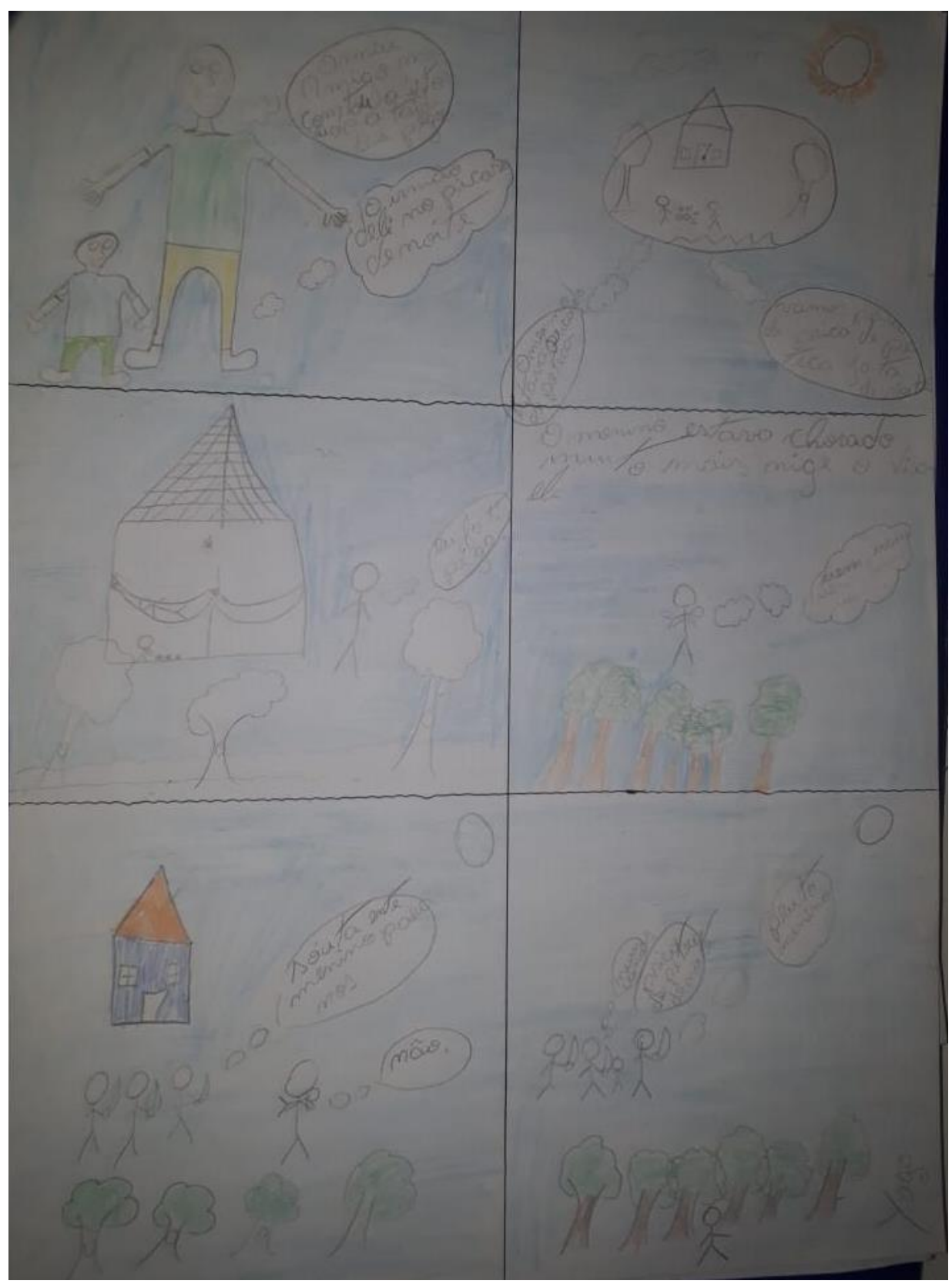

Fonte: Produção de crianças sobre o mito do Ataíde (2018)

Na figura 5 a discente conta a estória de uma criança que brincava de peteca durante a noite em uma praia conhecida como Picanço. Durante a brincadeira o Ataíde aparece para o menino dizendo que vai pega-lo e leva-o para dentro da mata, porém as pessoas escutavam os gritos do menino, mas não conseguem vê-lo. Logo, as pessoas armadas

@rquivo Brasileiro de Educação, Belo Horizonte, v. 6, n. 14, mai-ago, 2018. 
começaram a gritar para o Ataíde soltar o menino, no entanto, ele dizia que não soltaria.

Nesse relato percebe-se a presença do ser fantástico como repreensor de momentos lúdicos durante o horário noturno. Nas concepções de Unger (2001) é preciso que o ser humano se coloque em estado de disponibilidade para acolher o sentimento profundo das coisas e a revelação dos mistérios da natureza. Dessa forma, compreendemos que os fatos ocorridos durante a noite são decifrados sinais de que a existência da natureza é um elemento vivo.

A marca da cultura mitológica, como uma narrativa reproduzida entre as crianças que habitam as margens de manguezais se configuram de forma diferenciada entre as mesmas, uma vez que dependendo da idade, essas crianças recontam essas estórias e apresentam os seus significados de acordo com o que foi repassado pela geração mais antiga.

Logo, a versão contada pelas crianças podem se contrariar as versões consideradas pelos adultos, pois como o Ataíde é um ser que apresenta características diferenciadas de outros seres que vivem na mata, muitas vezes o adulto se limita a retratar a verdadeira identidade do Ataíde.

De acordo com as produções em quadrinhos as crianças dissertam narrativas do mito do Ataíde e reconstroem suas imaginações. Cascudo (2009) afirma que o mito, não é diferente de outras manifestações poéticas orais, apresenta particularidades que revelam informações históricas, sociais e etnográficas, constituindo-se em documento vivo. No entanto as narrativas efetuadas entre gerações apresentam grande significado para manter viva a história da comunidade local. Mediante essas narrativas constituídas em quadrinhos, as crianças apresentam também produções escritas, as quais contemplam a fábula existente no habitat de manguezais.

@rquivo Brasileiro de Educação, Belo Horizonte, v. 6, n. 14, mai-ago, 2018. 


\section{PRODUÇÃO TEXTUAL: CONSTRUINDO IMAGINÁRIOS ENTRE RIOS E MANGUES}

A aproximação dos humanos com o ecossistema produtivo está relacionada diretamente às formas de apropriação do ambiente. As populações a partir do processo migratório ocuparam a área de mangue estabelecendo nela uma relação de dependência. Essa relação com o mangue corresponde a uma teia de necessidades que além de ser parte natural da biologia aquática, são inter-relacionadas à cadeia existencial dos seres, os quais são co-responsáveis pelo processo de funcionamento do ecossistema.

Na Amazônia os rios exercem uma significativa importância para os seus habitantes. Segundo Pinto(2008, p.2) "[...] os próprios rios manifestam-se como agente de fertilização na medida em que possuem $\circ$ poder de inundar, submergir, irrigar ou fazer perecer a vida no caso de esgotamento de suas nascentes ou algum incidente natural". Ainda corrobora que "[...] o rio não é apenas um bem natural, mas, proporciona a vida a diversos seres que dependem desse habitat para sobreviver".

Pensar na Amazônia em meio aos seus rios e suas riquezas naturais é refletirmos também acerca dos mitos que compõem o imaginário do Norte do Brasil. Na concepção de Freitas o mito: "[...] é radical de mitologia, relatando estórias de personagens fabulosos ou heroicos, geralmente com cunho simbólico. Trata-se de uma narração de caráter fantástico, envolvendo o sobrenatural e artifícios explicativos da realidade ou da natureza [...]" (FREITAS et al., 2018, p. 145).

O mito não pode ser considerado como uma narrativa ou uma fala qualquer, pois apresenta suas especificidades, uma vez que suas marcas são simbolizadas pelo ser humano, que se tornam linguagens capazes de produzir algum tipo de narrativa. Nesse processo o mito não desaparece, continua na memória de adultos e crianças. Sendo assim, as construções das

@rquivo Brasileiro de Educação, Belo Horizonte, v. 6, n. 14, mai-ago, 2018. 
narrativas são lembradas em produções textuais.

Na construção histórica via produção textual a aluna enfatiza:

Era uma vez, um pequeno Ataíde no manguezal sozinho e um pequeno dia ele encontrou uma ilha deserta, [...] ficou incomodado, pois o Ataíde estava sempre de olho naquela pequena ilha, porque sempre tinha um homem que queria acabar com esse lugar, ele não gostava de homem que acabasse com a ilha dele. E em um determinado dia o Ataíde se invocou com o homem e então se escondeu atrás de uma árvore e ficou lá observando o homem, e quando o homem veio cortar a árvore, o Ataíde ficou muito invocado e encantou o homem e nunca mais esse homem veio mexer com as coisas dele(ALUNA ALMIRA).

Nas palavras da aluna fica claro que a figura do Ataíde é encarregada de proteger o ambiente natural das práticas exploradoras do homem. Ainda em entrelinhas subtende-se que o ser não humano observa as atitudes dos homens, buscando sempre intervir na destruição do seu habitat.

Via produção textual o aluno mostra que o Ataíde é um mito do manguezal, é um ser que não aprova determinados tipos de brincadeira sem horário noturno, uma vez que o barulho é um incômodo para esse ser misterioso. Segundo ele:

Muitos anos atrás no Picanço ${ }^{2}$ um menino estava brincando de peteca de noite quando apareceu o Ataíde e o levou para o manguezal, só que o menino chorov e os homens acordaram e foram atrás do Ataíde e pegaram o menino e nunca mais o menino brincou de peteca à noite (ALUNO IVAN).

Na narrativa, observou-se que as brincadeiras realizadas por crianças a noite, não é algo aprovado pelo Ataíde e por conta desse episódio as mudanças de comportamento nessa comunidade entre as crianças são modificadas. Essas modificações presentes no comportamento das crianças

\footnotetext{
${ }^{2}$ Picanço refere-se a uma praia localizada próxima a comunidade Castelo em Bragança-Pará.
}

@rquivo Brasileiro de Educação, Belo Horizonte, v. 6, n. 14, mai-ago, 2018. 
surgem a partir do momento que seus familiares se apropriam dessa história para inibir as crianças de brincar durante esse horário. Em prol dessa história repassada pelos mais velhos, as crianças absorvem essa teoria de forma positiva para que sua vida não seja ameaça. Nessa perspectiva, também ocorre a transformação da cultura em relação ao horário de lazer na comunidade, sendo assim uma das formas também utilizada pelos familiares para educar as crianças dessa localidade.

Nas palavras de LEANDRA o protetor do mangue tem uma mulher que é usada pelo Ataíde para atrair as suas vítimas, que geralmente são os pescadores. A esse respeito relata:

Era uma vez, um Ataíde que vivia no manguezal e quando o pescador ia pescar, ele adormecia os pescadores, depois levava para o manguezal, e ele tinha um cheiro fedido, quando ele não ia, ele mandava a sua mulher. Quando a mulher gostava de algum dos homens ela dançava e conquistava os homens, depois de encantado levava para o Ataíde, o qual matava(ALUNA LEANDRA).

Nessa afirmativa, o personagem Ataíde apresenta uma relação afetiva com um ser que exibe suas mesmas características, porém do sexo oposto. Diante desse relacionamento entre Ataíde macho e Ataíde fêmea, a mesma encontra-se em nível de desigualdade em relação ao seu companheiro, pois esta realiza algumas práticas que são impostas pelo macho. Diante disso percebe-se que os seres mitológicos apresentam sexo diferente, logo "ser identificado como masculino e feminino é um dado natural e biológico, assim como uma consequência da identificação genitália [...]" (SIMÃO, 2013, p.179). Nessa perspectiva o gênero é destacado para diferenciar o sexo, no entanto essa determinação biológica entre o ser mitológico comunga em uma relação de poder em que o sexo masculino se apropria de sua masculinidade para demonstrar autoritarismo e poder sobre a figura do gênero feminino.

@rquivo Brasileiro de Educação, Belo Horizonte, v. 6, n. 14, mai-ago, 2018. 
Mediante a essa assertiva, as relações de gênero se configuram como cultura que reforça o patriarcalismo, na qual o mito do Ataíde também se insere nesse contexto, uma vez que esse mito é apontado em realizar práticas que geralmente estão presente entre os sujeitos ribeirinhos. Esse tipo de postura determina que a cultura dessa comunidade em redor de manguezais aponta para a figura de homens que comungam de práticas machistas.

Essa forma de retratar o Ataíde fêmea como inferior, influencia na postura das crianças que convivem nesse espaço, uma vez que elas se reproduzem nas vozes dos mais experientes. Entretanto, as práticas das crianças podem se tornar normal, por acreditarem na existência de uma hierarquia que não estar presente somente entre os humanos, mas entre os mitos, mas também podem se tornar contrarias a esses estereótipos e se tornarem capazes de reconstruir seu posicionamento. De acordo com o autor:

[...] geralmente as crianças são dicotômicas e contraditórias, mas às vezes se tornam resistentes e desafiam a determinação de determinados estereótipos, mas também podem atualizar reproduzir e acentuar esses mesmos estereótipos. [...]. (SIMÃO2013, p.181).

As crianças, nessa visão podem herdar ou não aquilo que thes é ensinado enquanto verdade. Para tanto, educar as crianças por meio da explicação do mito é recorrente nessa localidade. O mito se encarrega de uma possível explicação e interpretação da realidade ou de um acontecimento.

Para a aluna Luana o Ataíde é representado como:

[...] um bicho muito assustador e um dia uma pessoa me falou que viu um Ataíde na praia do Picanço e que o Ataíde ficou olhando muito sério para ela e logo tentou correr, mas conseguiu chamar o amigo, que pegou um pedaço de pau e

@rquivo Brasileiro de Educação, Belo Horizonte, v. 6, n. 14, mai-ago, 2018. 
dele um monte de cassetada no Ataíde e ele foi embora, mas no outro dia o Ataíde apareceu para ela novamente, então ele pegou um pau e partiu para cima da fera, mas ele não correu, porque só corre de homem"(ALUNA LUANA).

Nas palavras da aluna percebemos que a atitude desse ser fantástico ocorre em diferentes lugares praieiros e com pessoas de sexo masculino e feminino; no entanto a presença da mulher, mesmo que esteja com um objeto para se defender, ele não se assusta, mas apresenta diferente reação na presença do homem, ou seja, este não se intimida com a reação do gênero feminino, no entanto o homem lhes causa susto.

Diante disso, é explicito que a relação dessa criatura com a mulher se dá de forma diferenciada em relação ao sujeito do sexo masculino, uma vez que pode ser considerada como sensível, não apresentando perigo para esse ser dos manguezais. Para Seleprin (2016) os mitos reproduzem práticas criadoras e significativas que sustentam a permanência da realidade constituída.

\section{CONCLUSÃO}

A forma como cada criança ouve uma história, estabelece uma percepção diferente sobre os seres mitológicos, no caso, a estória do Ataíde tecida de geração a geração mostra questões relacionadas à forma de proteção que esse ser habita nos manguezais. Diante disso, percebemos que as crianças, assim como os adultos, acreditam na existência desse ser sobrenatural.

Nesse sentido, evidenciamos que as crianças são os principais personagens encarregados de manter viva a existência deste ser simbólico, uma vez que este apresenta grande relevância para as comunidades ribeirinhas, por ter seu papel de protetor e controlador do uso do espaço natural. Este ser fabuloso é capaz de modelar o comportamento dos seres

@rquivo Brasileiro de Educação, Belo Horizonte, v. 6, n. 14, mai-ago, 2018. 
humanos, para assim determinar respeito e poder de autoridade no seu setor de vivencia.

O mito na figura do Ataíde é capaz de impor regras em seu ambiente e modificar as ações do homem frente a natureza, além disso demonstra que o seu poder de autoridade se sobrepõe a figura do gênero feminino. Consequentemente, percebe-se que as atitudes do Ataíde às praticas de aviltamento do homem no tocante a mulher.

Dessa forma, a mitologia reconstruída pelas crianças que habitam as margens de manguezais contribui para que os saberes tradicionais permaneçam e passem de geração a geração criando um vínculo afetivo ao seu lugar, produzindo uma forma própria de viver e se relacionar com a natureza, tradições e crenças que os distinguem dos demais grupos sociais.

A cultura mitológica estabelece diferentes relações com o meio natural, as histórias que são contadas no enlace familiar, direcionam para que elas tenham um vínculo com a natureza e dessa maneira possa gerar atitudes benéficas ao meio ambiente.

O entendimento das mais variadas relações homem-natureza, que vão desde o simples ato de contemplar uma paisagem, passando por estratégias para a pesca e o modo como contribui para o meio ambiente tirando apenas o necessário para sua sobrevivência sem degradar o seu espaço de vivência, gerando uma relação de respeito com o habitat do dono do mangue.

Em suma, o mito configura-se como um elemento presente entre as gerações por meio da força da oralidade, e que o encarregado de repassar esse conhecimento mitológico nem sempre é a família, mas são responsáveis por essa aprendizagem sujeitos mais velhos que convivem diariamente no trabalho realizado no mangue. Essa cultura é singular de comunidades ribeirinhas, as quais comungam dessa identidade como parte significativa que traz sentido a construção histórico social dessa localidade.

@rquivo Brasileiro de Educação, Belo Horizonte, v. 6, n. 14, mai-ago, 2018. 


\section{REFERÊNCIAS}

CASCUDO, Luis da Câmara. Literatura oral no Brasil. 2. ed. São Paulo: Global Editora, 2009.

CHARTIER, Roger. A história cultural entre práticas e representações.

Tradução de Maria Manuela Galhardo. Lisboa: Difusão Editora, 1988.

CHARTIER, Roger. O mundo como representação. Estudos avançados, São Paulo, v. 5, n.11, jan./abr. 1991.

DIEGUES, Antonio Carlos. (org.). et al. Os saberes tradicionais e biodiversidade no Brasil. São Paulo: MMA/NUPAUB/USP, 2000.

DUARTE, Rosália. Pesquisa qualitativa: reflexões sobre o trabalho de campo. Cadernos de Pesquisa, n. 115, mar. 2002.

ELIADE, Mircea. Mito e realidade. São Paulo: Perspectiva, 1972.

A LENDA do negro Ataíde. [S. I.]: Visagento, 2012. Disponível em: http://visagento.blogspot.com.br/2017/05/lenda-do-negroataide.html. Acesso em 05 nov. 2018.

FREITAS, Ádria C. et al. Lendas, misticismo e crendices populares sobre manguezais. In: PINHEIRO, Marcelo Antonio Aamaro; TALAMONI, Ana Carolina Biscalquini. (org.). Educação Ambiental sobre Manguezais. São Vicente: UNESP, 2018. p. 144-164.

GATTI, Bernadete. Implicações e Perspectivas da pesquisa educacional no país. Cadernos de Pesquisa, n. 113, p. 65-81, jul. 2001.

MINAYO, Maria Cecília de Souza (org.). Pesquisa Social: teoria, método e criatividade. 18 ed. Petrópolis: Vozes, 2011.

MOYA, Álvaro. História das histórias em quadrinhos. São Paulo: Brasiliense, 1994.

PINTO, Mariliana C. Oliveira Bessa Serra. A Amazônia e o imaginário das águas. Disponível em:

http://www.ppgsocio.ufam.edu.br/attachments/038_A\%20Amaz\%C3\%B4nia\% 20e\%200\%20imagin\%C3\%A 1 rio\%20das\%20\%C3\%Al guas.pdf. Acesso em: 10 nov. 2018.

ROCHA, Everaldo. O que é mito. São Paulo: Brasiliense, 1996.

@rquivo Brasileiro de Educação, Belo Horizonte, v. 6, n. 14, mai-ago, 2018. 
SANTOS, José Luiz dos. O que é cultura. São Paulo: Brasiliense, 1994.

SELEPRIN, Maiquel José. O mito na sociedade atual. [S. I.]: Educadores dia a dia, 2016. Disponível em:

http://www.educadores.diaadia.pr.gov.br/arquivos/File/2010/artigos_teses/Fl LOSOFIA/Artigos/O_mito_na_sociedade_atual.pdf. Acesso em: 07 nov. 2018.

SOCORRO, Maria do. Lendas e mitos da Amazônia. Revista Litteris Literatura, n. 5, jul. 2010.

SIMÃO, Márcia Buss. Relações sociais de gênero na perspectiva de crianças pequenas na creche. Cadernos de Pesquisa, v. 43, n. 148, p. 176-197, 2013.

UNGER, Nancy Mangabeira. Da foz à nascente: o recado do rio. Campinas: Editora da Unicamp, 2001.

VIEIRA, Norma Cristina et al. Trabalho e gênero em comunidades extrativistas da costa paraense. Caderno Espaço Feminino, Uberlândia, v. 28, n. 1 , jan./jun. 2015.

@rquivo Brasileiro de Educação, Belo Horizonte, v. 6, n. 14, mai-ago, 2018. 